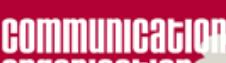

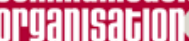

\section{Communication et organisation}

Revue scientifique francophone en Communication

organisationnelle

\section{$53 \mid 2018$}

Digitalisation et recrutement : perspectives

informationnelles et communicationnelles

\title{
Craig BROWNE, Critical Social Theory
}

London : SAGE Publications Ltd. 2017, VI-208 p

\section{Eloria Vigouroux-Zugasti}

\section{OpenEdition}

\section{Journals}

Édition électronique

URL : https://journals.openedition.org/communicationorganisation/6429

DOI : 10.4000/communicationorganisation.6429

ISSN : 1775-3546

Éditeur

Presses universitaires de Bordeaux

Édition imprimée

Date de publication : 1 juin 2018

Pagination : 234-235

ISBN : 979-10-300-0302-4

ISSN : 1168-5549

Référence électronique

Eloria Vigouroux-Zugasti, «Craig BROWNE, Critical Social Theory », Communication et organisation [En ligne], 53 | 2018, mis en ligne le 01 juin 2018, consulté le 29 janvier 2022. URL : http:// journals.openedition.org/communicationorganisation/6429 ; DOI : https://doi.org/10.4000/ communicationorganisation.6429 
CARAYOL Valérie, 2005, Principe de contrôle, communication et temporalités organisationnelles. Études de communication, 2005, N² 28, p. 77-89.

CARAYOL Valérie (Dir.), 2005, Vivre l'urgence dans les organisations. Paris : L'Harmattan.

ROSA, Hartmut, 2014, Aliénation et accélération: vers une théorie critique de la modernité tardive. Paris : La Découverte.

\section{Craig BROWNE, Critical Social Theory. London : SAGE Publications Ltd. 2017, VI-208 p.}

Cet ouvrage est proposé par le chercheur australien Craig Browne, Maître de Conférences (senior lecturer) au département de sociologie et de politique sociale de l'Université de Sydney. Il est également investi dans de nombreux mouvements et organisations dédiés à l'étude de la sociologie (European Sociological Association, Research Network on Social Theory, International Sociological Association, etc.). Ses intérêts de recherche portent sur les imaginaires sociaux, la philosophie de la praxis, la critique ou encore l'intersubjectivité et le changement social. Critical Social Theory propose d'appréhender, d'un point de vue critique, des concepts sociologiques connus : reconnaissance, postmodernisme, aliénation, changement social, etc. L'abondante culture sociologique de l'auteur et sa réflexion conceptuelle originale aboutissent à un ouvrage riche et captivant.

Craig Browne se propose ainsi d'aborder un impressionnant éventail de théories sociologiques. Si le nombre de références et de théories est imposant, le caractère propédeutique de l'ouvrage l'est encore plus. En effet, l'argumentation de l'auteur, par sa rigueur scientifique et par son abord original, amène davantage de questions que de réponses. Partant d'une approche critique des théories sociologiques, l'auteur propose de nouvelles problématiques, de nouveaux questionnements, riches et profonds, suggérant alors de très nombreuses pistes de réflexion pour le lecteur.

L'ouvrage se compose de six chapitres : le changement social, la reconceptualisation de l'aliénation, le système d'intégration et d'exclusion sociale, la fin de la critique immanente, la liberté positive et la justice sociale, pour conclure sur la liberté et l'autonomie sociale. Chaque chapitre propose une courte introduction aux concepts qu'il traite, suivie d'une argumentation critique sur ces mêmes courants. Une conclusion vient faire la synthèse de chaque chapitre, en proposant également des ouvertures et des pistes de réflexions au lecteur. 
Le principal point faible de cet ouvrage repose sur sa forme, parfois difficile d'accès. L'auteur manie des concepts et des paradigmes complexes, supposant un certain niveau de culture sociologique et philosophique de la part du lecteur. Malgré tout, cette complexité est largement rattrapée par la démonstration théorique de l'auteur. Une fois la première impression de lourdeur dépassée, le lecteur accède à une argumentation riche, renseignée, pertinente et convaincante. La structuration commune des chapitres soutient le cheminement du lecteur, au fil des pages, puisqu'elle propose une même organisation claire et structurée de l'argumentaire. Craig Browne, au cours des quelque 170 pages de louvrage, avance une vision passionnante des courants sociologiques classiques.

Ce livre s'impose comme un incontournable pour les chercheurs en sciences sociales. Chez les jeunes chercheurs, l'argumentation participe à l'enrichissement de leur culture et de leur pensée scientifique, en proposant des points de vue complémentaires aux théories sociales connues. Il encourage ainsi les jeunes chercheurs à développer des idées originales et novatrices. Aux chercheurs aguerris, cet ouvrage offre de nouvelles pistes de développement et de débats, encourageant ainsi l'approfondissement des recherches sociologiques.

Nous aimerions conclure sur la qualité de Critical Social Theory. Sa lecture nécessite une importante acculturation du lecteur au domaine de la sociologie et à ses courants les plus connus. Cependant, l'ouvrage de Craig Browne présente une profondeur de réflexion et une pertinence argumentaire dépassant ces quelques difficultés de lecture. La force de ses démonstrations et de ses raisonnements rend la lecture de cet ouvrage indispensable pour tout chercheur souhaitant dépasser les rhétoriques classiques de la sociologie. Critical Social Theory ouvre le lecteur à de nouveaux horizons et l'invite à sortir des sentiers battus pour explorer de nouvelles pistes de réflexions scientifiques.

\section{Eloria VIGOUROUX-ZUGASTI²}

\footnotetext{
2- Eloria Vigouroux-Zugasti est docteure en sciences de l'information et de la communication à L'Université Bordeaux Montaigne (laboratoire MICA EA 4426). Spécialisée dans l'étude des usages numériques, notamment dans leur appropriation par les retraités, elle s'intéresse également aux questions de littératie informationnelle/digitale de santé ainsi qu'aux questions alliant lien social et sciences de l'information et de la communication.
} 